\title{
La cuestión catalana: origen, desarrollo, y perspectivas
}

\author{
José E. De Ayala
}

\section{$\rightarrow$ Resumen}

Cataluña es una de las regiones más ricas de España y, gracias a su Estatuto de Autonomía, goza de un autogobierno comparable al existente en los Estados federales. Ha sido parte de España desde que España existe, pero a lo largo de la historia ha habido varios episodios de desacuerdos e intentos de independencia. Desde principios de este siglo, los partidarios de la secesión han iniciado un proceso de soberanía, ignorando la Constitución y la legalidad española, que culminó, en octubre de 2017, con una declaración unilateral de independencia, que implicó una intervención temporal de su autogobierno por parte del Gobierno español y el juicio y condena de sus principales líderes, además de no ser reconocida por ningún país $u$ organización internacional en el mundo. La sociedad catalana es plural, formada en parte por emigrantes de otras partes de España, y está muy dividida sobre este tema. Los partidarios de la independencia nunca han logrado obtener el 50\% de los votos en ninguna de las numerosas elecciones celebradas, aunque hay una mayoría favorable a aumentar el nivel de autonomía. La solución a este conflicto solo puede venir con el logro de un acuerdo político que establezca una nueva relación entre Cataluña y el resto de España, que satisfaga a la mayoría, sin la necesidad de romper. Pero esta solución será difícil tanto por el radicalismo de algunos líderes separatistas como por la falta de acuerdo entre los partidos españoles sobre cómo abordar la cuestión.

\section{$\rightarrow$ Palabras clave}

Cataluña, España, autonomía, historia, proceso, independencia, secesionismo

Declaración de divulgación: El autor no informó de ningún posible conflicto de intereses. https://doi.org/10.46272/24093416-2020-8-2-42-64

Artículo de investigación

José Enrique de Ayala, Miembro del Consejo Asesor y del Consejo de Asuntos Europeos,

Observatorio de Politica Exterior de la Fundación Alternativas, Madrid (España)

E-mail:

enriqueayalamarin@gmail.com

Para la correspondencia: 28001 , España, Madrid, Don Ramón de la Cruz, $39-1^{\circ}$ Izda

Para citar: De Ayala, José Enrique. "La cuestión catalana: origen, desarrollo, y perspectivas" [The Catalan issue: origin, development and prospects]. Cuadernos Iberoamericanos 8, no. 2 (2020): 42-64. https://doi. org/10.46272/2409-3416-20208-2-42-64. [In Spanish]

El artículo fue recibido por los editores: 19.06.2020

Aceptado para publicación: 02.08.2020 
El territorio de Cataluña se sitúa geográficamente en el noreste de la península ibérica, salvo una pequeña parte, denominada actualmente Catalunya Nord que está al norte de los Pirineos y pertenece a Francia desde el Tratado de los Pirineos de 1635. Su superficie, $32.108 \mathrm{~km} 2$, representa un 6,34\% de la española, y su población, 7,566 millones, un 16,12\% del total. Su Producto Interior Bruto anual, 228.682 millones de euros (2018), es el segundo entre las Comunidades Autónomas españolas, ligeramente por detrás de Madrid, y supone un 19\% del total. ${ }^{1}$ Tomado per cápita, 30.426 euros (2018), es el cuarto, solo por detrás de Madrid, País Vasco y Navarra. Es, por tanto, una de las comunidades más importantes y más ricas de España.

Políticamente, se constituye como una de las 17 Comunidades Autónomas que - junto con dos ciudades autónomas - forman el Estado español, y que se corresponden en general con las regiones históricas. Cataluña dispone de su propio Gobierno, su Parlamento, su Tribunal Superior de Justicia, su lengua propia - cooficial con el castellano - e incluso su propia policía. Es una de las comunidades con mayor autogobierno de España, por detrás del País Vasco, y tiene competencias propias en asuntos tan importantes como sanidad, educación y asuntos sociales, entre otras. Su grado de autogobierno, es comparable en muchos aspectos - no en todos - al de los länder alemanes, lo que le ha permitido en los últimos años alcanzar los niveles de desarrollo económico y cultural más importantes de su historia.

No obstante, su relación con el resto de España ha sido conflictiva en algunas ocasiones en el pasado, y en la actualidad esta relación está sufriendo una crisis que pone en cuestión el modelo territorial de la Constitución de 1978, y se ha convertido en el principal problema de la democracia española, ya que una parte de los partidos políticos catalanes, apoyados por casi la mitad de la población, han intentando conseguir la secesión de la región para convertirla en un Estado independiente. Este intento solo ha conseguido, como veremos, agudizar la división y la tensión política, tanto en el seno de Cataluña, como en el resto de España.

\section{Las raices históricas del conflicto}

Cataluña ha formado parte de España, siempre que el concepto España ha existido en la historia, salvo un breve periodo en el siglo XVII en que estuvo de facto bajo soberanía del rey de Francia. Formó parte de la Hispania romana, que existió entre el siglo III a.C. y principios del siglo V d.C., primero en la provincia de Hispania Citerior y después en la Tarraconensis, en ambos casos junto a otras regiones de la península ibérica. También fue parte de la Hispania visigoda, que sucedió a la romana entre mediados del siglo $V$ y principios del siglo VIII, y mantuvo en líneas generales su división territorial. En el año 711, comenzó la invasión del reino visigodo por los musulmanes Omeyas procedentes del norte de África, que en diez años ocuparon toda la península ibérica, llegando en el año 736 hasta Poitiers, en el centro de la actual Francia, donde fueron derrotados y rechazados por el caudillo franco Carlos Martel. Su sucesor, Carlomagno, intentó hacer retroceder a los musulmanes al menos hasta el rio Ebro, pero fracasó y creó, a finales del siglo VIII, una zona de contención al sur de los Pirineos que se conoció con el nombre de Marca Hispánica, para asegurar el límite con al-Andalus musulmán que ocupaba entonces el resto de la península con la excepción del núcleo asturiano.

La Marca Hispánica abarcaba, en el momento de su máxima extensión, desde el mar Mediterráneo hasta Pamplona, y nunca constituyó una unidad administrativa o política. Se trataba de un conjunto de condados, dependientes de los reyes carolingios 
que nombraban a los condes, bien de origen franco o de origen visigodo según los casos. En el territorio de lo que hoy es Cataluña los primeros condados fueron Barcelona, Gerona, Ampurias, Rosellón y Urgel-Cerdaña, que se constituyeron entre finales del siglo VIII y principios del IX, entre los cuales el condado de Barcelona se convirtió enseguida en el más importante. A finales del siglo IX la decadencia del imperio carolingio propició una independencia de facto de los condados de la Marca Hispánica, que pasaron a ser hereditarios. El primer conde de Barcelona autóctono, que inauguró su propia dinastía, fue Wilfredo el Velloso en 878, gobernando sobre unos dominios que se extendían además a los condados de Cerdaña y Gerona, y posteriormente también al de Osona, a los que se unieron, ya a principios del siglo XII, los de Berga y Besalú. En 1137 se produce la unión dinástica entre el condado de Barcelona, que reunía ya por tanto una parte importante de lo que hoy es Cataluña, con el reino de Aragón, a través del matrimonio de la heredera de éste, Petronila, hija del rey de Ramiro II de Aragón, con el conde de Barcelona Ramón Berenguer IV, que empieza a ostentar también el título de príncipe de Aragón. El hijo de ambos, Alfonso II es, a partir de 1164, el primer monarca de la que pasó a denominarse Corona de Aragón y ostenta, al igual que sus sucesores, el título de conde de Barcelona.

Conviene subrayar que la unión no fue de Aragón con Cataluña, sino con el condado de Barcelona, porque Cataluña no existía como unidad política o administrativa en aquella época. Aunque las primeras menciones a ese nombre con carácter geográfico se encuentran en un documento fechado hacia 1117, la denominación Principado de Cataluña no aparece documentalmente hasta 1350, es decir casi doscientos años después de su integración en la corona de Aragón. De hecho, la mayor parte del territorio de la actual Cataluña solo formaria parte de la Corona de Aragón después de la unión dinástica. Tortosa y Lérida fueron conquistadas por el propio Ramón Berenguer IV en 1148 y 1149, el condado de Ampurias se incorporó en 1325, el Valle de Arán en 1411, el condado de Urgel en 1413, y el condado de Pallars Sobirá en 1491. El título de principado que ostenta Cataluña desde el siglo XIV tiene un carácter jurídico, se refiere al territorio que está bajo la jurisdicción de las Cortes catalanas que se constituyeron en el siglo XIII. A pesar de la unión con Aragón, el condado de Barcelona primero, y el principado de Cataluña después, mantuvieron sus propias leyes y fueros, como sucedió en otras partes de España, aunque en ningún momento este territorio se constituyó como reino. Es decir, en contra de los intentos de los círculos y partidos políticos independentistas actuales, por manipular o interpretar sesgadamente la historia, lo cierto es que Cataluña no ha sido nunca independiente, ni ha constituido una entidad política propia y unificada hasta mucho después de su integración en la Corona de Aragón.

En 1469, el matrimonio de Fernando II de Aragón con Isabel de Castilla, conocidos como los Reyes Católicos produjo la unión dinástica de las dos principales coronas peninsulares, aunque cada una continuó siendo independiente. Esta unión se completaría con la conquista del reino de Granada - último reducto musulmán en la península - en 1492 y la anexión del reino de Navarra en 1512. Portugal no se uniría al resto de reinos peninsulares hasta 1580, y solo por un breve período de tiempo. A la muerte de Isabel, Fernando pasó a ser regente de Castilla, ante la incapacidad de su hija Juana, hasta su muerte en 1516. Su nieto, Carlos I, fue el primer monarca de todos los reinos hispánicos, incluyendo la Corona de Aragón, y dentro de ella el principado de Cataluña, aunque los distintos reinos continuaron teniendo sus propios fueros e instituciones durante toda la época que reinó en España la casa de Habsburgo, también denominada de Austria, a la que pertenecía por herencia paterna Carlos I, que fue asimismo emperador del Sacro Imperio Romano Germánico con la denominación de Carlos V. 
El primer conflicto importante que enfrentó a Cataluña con el poder real se produjo en 1640, en el marco de la guerra de los 30 años (1618-1648), que supondría la pérdida de la condición de España como potencia hegemónica europea a favor de Francia. La sublevación de Cataluña, llamada de los segadores, tuvo como causa inmediata la pretensión del Conde-Duque de Olivares, valido del rey Felipe IV, de imponer una llamada Unión de Armas según la cual Cataluña debería aportar 6.000 hombres a los ejércitos reales para contribuir al esfuerzo bélico, sin que esta medida hubiera sido aprobada por las Cortes catalanas, pero también influyó la decadencia política y económica de Castilla, el rechazo a la presencia de tropas castellanas territorio catalán, y las maniobras de Francia que, para debilitar a España con quien había entrado en guerra en 1635, animó tanto esta sublevación como la de Portugal - que conseguiría la independencia en 1640 - y la de Nápoles en 1647. Desde 1640 Cataluña pasó a estar bajo protección de Francia, y desde 1641 el rey de Francia fue también conde de Barcelona, es decir, en ningún momento Cataluña fue independiente, ni siquiera de facto. Los catalanes tuvieron que sufrir de los franceses lo que habían querido evitar de los castellanos, y a veces con mayor dureza, lo que produjo un importante descontento en la población. En 1652 el ejército de Felipe IV rinde Barcelona, acabando con la sublevación. La paz de los Pirineos, firmada con Francia en 1659, consagró la separación de una parte de Cataluña, el Rosellón y el norte de la Cerdaña, que han estado desde entonces bajo soberanía francesa.

El siguiente episodio de mayor confrontación se produjo a raíz de la llamada Guerra de Sucesión (1701-1713) que enfrentó a las casas de Borbón y de Austria, apoyadas respectivamente por Francia y por el Sacro Imperio Romano Germánico, que se disputaban el trono de España después de la muerte sin descendencia de Carlos II. Como los borbónicos encontraron su mayor apoyo en Castilla y la mayor parte de la Corona de Aragón era austracista, sobre todo por recelo del centralismo borbónico que después se confirmaría, la guerra, que fue europea en su conjunto con batallas en varios países, se convirtió en el interior de España casi en una guerra civil. Las tropas de Felipe V, primer rey de la casa de Borbón, ganaron la guerra en el interior de la península culminando con la toma de Barcelona el 11 de septiembre de 1714. Las consecuencias para Cataluña fueron desastrosas. Inmediatamente se suprimieron las Cortes catalanas y todo el resto de instituciones propias de Cataluña, que no volvería a tener alguna hasta la creación de la Mancomunidad de Cataluña 200 años después. En 1716, los decretos de nueva planta, que afectaron también al resto de los territorios de la Corona de Aragón, confirmaron la unificación de las instituciones siguiendo el modelo de Castilla y la supresión de cualquier ley o institución propia de Cataluña, excepto el derecho civil que continuó estando vigente, tanto como consecuencia del castigo impuesto por su apoyo al candidato de la casa de Austria, como por el centralismo político inherente a los deseos de la casa de Borbón, como ya se había establecido en Francia.

Las tres guerras civiles, conocidas como Guerras Carlistas, que enfrentaron en España a liberales con tradicionalistas por razones dinásticas a lo largo del siglo XIX, tuvieron también un importante impacto en Cataluña, especialmente las dos últimas, pero no se pueden considerar en ningún caso como una confrontación entre Cataluña y Castilla o el resto de España, porque en Cataluña hubo - como en todo el resto de España partidarios de ambos bandos, manteniéndose las ciudades casi siempre en el bando liberal. En ningún momento Cataluña en su conjunto fue partidaria de ninguno de los pretendientes carlistas al trono, a pesar de que uno de ellos Don Carlos - Carlos VII para sus seguidores se comprometió en 1872 a restaurar los fueros e instituciones abolidos por los decretos de 
nueva planta. No obstante, la diferencia entre el mundo rural, amante de las tradiciones, donde el carlismo encontró más apoyo, y el urbano, más liberal y cosmopolita, tiene todavía hoy algún reflejo en la realidad política de Cataluña.

En la segunda mitad del siglo XIX, se produce en toda Europa un auge de los nacionalismos, al hilo de los movimientos románticos que exaltan las raíces históricas, culturales y étnicas de los pueblos, movimientos que conducen a la unificación de Italia y Alemania, y que darian lugar después de la Primera Guerra Mundial a la disolución de los imperios y la creación de los Estados-nación en Europa, de acuerdo con los principios del Presidente de EEUU, Woodrow Wilson, y a la independencia de muchas naciones europeas, entre ellas la República de Irlanda. Estas doctrinas desarrolladas sobre todo por filósofos alemanes como Johann Gottfried Herder y Johann Gottlieb Fichte propiciaron en España el surgimiento de los nacionalismos modernos en el País Vasco (creación del Partido Nacionalista Vasco, 1895) y en Cataluña, donde las teorías catalanistas de Valentí Almirall se concretarían en la creación, primero del Centre Catalá (1882) y luego de la Unió Catalanista que elaboró en 1892 las llamadas Bases de Manresa, ${ }^{2}$ consideradas el acta fundacional del catalanismo político, un movimiento que se desarrolló en los años siguientes y dio lugar a la creación de diferentes partidos, más o menos regionalistas, hasta que en 1922 Francesc Maciá crea Estat Catalá, el primer partido independentista, antecesor directo e inspirador de los movimientos independentistas actuales. En 1914 se había constituido la Mancomunidad de Cataluña, que agrupaba las Diputaciones de las cuatro provincias catalanas en un ente único, y que era por tanto - a pesar de sus muy limitadas funciones de coordinación regional - la primera institución propiamente catalana desde 1714.

El temprano auge de los nacionalismos vascos y catalán, que encontraron enseguida su modelo en el Sinn Féin irlandés, fue alentado por los intereses divergentes de una burguesía industrial y comercial que se desarrolla en Cataluña y en el País Vasco en la época, más moderna y próxima a Europa, frente al poder central anquilosado e ineficaz de la restauración borbónica, en el que el caciquismo de los propietarios agrarios de Castilla y Andalucía juega aún un papel determinante, y que no sirve ya a las necesidades políticas de las regiones más adelantadas. Este desencuentro se agudiza con el declive de la monarquía borbónica y sobre todo con "la crisis del 98" y la pérdida de Cuba (después de la Guerra hispano-estadounidense de 1989) que era muy importante para Cataluña. La llegada de la II República permitió a los partidos nacionalistas periféricos consolidarse y crecer hasta obtener el poder en sus respectivas demarcaciones.

El 14 de abril de 1931, horas antes de que se proclamara la República Española, Francesc Macía - que había ganado las elecciones dos días antes al frente de la recientemente creada Esquerra Republicana de Catalunya (ERC) - proclama desde el balcón del Palacio de la Generalitat el Estado Catalán "que con toda cordialidad intentaremos integrar en la Federación de Repúblicas Ibéricas", 3 una federación inexistente. Las autoridades republicanas, que tomaron posesión ese mismo día en Madrid, lograron convencer a Maciá de que no siguiera adelante con su iniciativa a cambio de la promesa de un Estatuto de Autonomía, ${ }^{4}$ que se concretó en 1932, por el que se restauraba la institución histórica de Generalitat, que había nacido como Diputación del General a finales del siglo XIII. En el llamado estatuto de Nuria, finalmente aprobado por las Cortes republicanas,

1 Almirall 2013

2 "Bases de Manresa (27 marzo 1892)," Fundación Biblioteca Virtual Miguel de Cervantes, accessed August 1, 2020, http://www.cervantesvirtual.com/obra-visor/bases-de-manresa-27marzo-1892/html/c7cb9e90-c4a0-4074-811d-7bdc620529d8_2.html.

3 Soldevila 1977, 46-48.

4 "Estatuto de autonomía de Cataluña (1932)," Fundación Biblioteca Virtual Miguel de Cervantes, accessed August 1, 2020, http://www.cervantesvirtual.com/obra/estatuto-de-autonomia-de-cataluna-1932/. 
no se recogía ninguna mención a la soberanía catalana, a pesar de que, en aquel momento, partidos como ERC ya reivindicaban el derecho de autodeterminación, que no fue en ningún momento reconocido por la República.

El 6 de octubre de 1934, después de que los partidos de derechas se hicieran con el Gobierno de la República en Madrid, Lluis Companys, presidente de la Generalitat proclamó solemnemente la creación del Estado catalán "dentro de la República Federal española", "que seguía sin existir con ese carácter federal. La iniciativa duró diez horas, hasta que el ejército logró vencer la escasa resistencia que ofrecieron los sublevados, y se saldó con 46 muertos y más de 3.000 personas arrestadas, entre ellas casi todo el Gobierno catalán con su Presidente. El Parlamento catalán fue clausurado y la Generalitat fue suspendida sine die, aunque fue restaurada a la llegada al poder del Frente Popular en febrero de 1936. En julio de ese mismo año, se produjo la sublevación militar que daría origen a la guerra civil española alineándose Cataluña con el bando republicano. El triunfo de los sublevados en abril de 1939 supuso el final de las instituciones catalanas - aunque la Generalitat sobrevivió nominalmente en el exilio, y la pérdida de todas las conquistas de autogobierno y difusión de la lengua catalana que Cataluña había obtenido hasta ese momento, inaugurando un período de casi 40 años en el que estuvo completamente supeditada al poder central de la dictadura franquista.

Con la llegada de la democracia, a la muerte del General Franco, la Generalitat fue restablecida provisionalmente, en un principio solo con carácter ejecutivo y sin apenas competencias, en septiembre de 1977 en la persona de Josep Tarradellas, que ostentaba en aquel momento la presidencia de la Generalitat en el exilio. Es significativo que esta restauración se produjo antes de la aprobación de la Constitución española por lo que en ese momento carecía de cualquier fundamento legal en la legislación, que todavía era la de la dictadura. La Constitución española fue sometida a referéndum el 6 de diciembre de 1978. En Cataluña fue aprobada por el 90,5\% de los votantes (2,6 puntos por encima de la media de España) con una participación del 67,9\% (también ligeramente por encima de la media). ${ }^{2}$ Según su Artículo 2 , la Constitución entonces aprobada por esa abrumadora mayoría, y actualmente en vigor "... se fundamenta en la indisoluble unidad de la Nación española, patria común e indivisible de todos los españoles, y reconoce y garantiza el derecho a la autonomía de las nacionalidades y regiones que la integran y la solidaridad entre todas ellas." ${ }^{3}$ En consecuencia, en diciembre de 1979 se promulgó un nuevo Estatuto de Autonomía, ${ }^{4}$ que restituía definitivamente la Generalitat y todas las instituciones catalanas, otorgándolas en la práctica más poder del que habían tenido nunca, al menos desde 1714, si bien la transferencia de algunas competencias se ha ido realizando con cierta parsimonia y no siempre exenta de tensiones con el Gobierno central. El Estatuto de Autonomía fue aprobado en referéndum con una participación del 59,7\% y un 88,1\% de votos afirmativos. ${ }^{5}$ Desde abril de 1980 hasta diciembre de 2003 el Presidente de la Generalitat fue Jordi Pujol, al frente de Convergencia y Unión (además - CiU), una coalición de dos partidos catalanistas de centro-derecha, que durante esa época dieron apoyo a diferentes gobiernos en Madrid, tanto de izquierdas como de derechas, contribuyendo a la estabilidad del sistema.

1 Jardi 1997, 69

2 "Referendum Constitución Española en otros ámbitos. 6 diciembre 1978," Ayuntamiento de Barcelona, accessed August 1, 2020,

https://www.bcn.cat/estadistica/castella/dades/telec/ref/ref78/r22.htm.

3 "Constitución Española," Agencia Estatal Boletín Oficial del Estado. Ministerio de la Presidencia, Relaciones con las Cortes y Memoria Democrática, accessed August 1, 2020, https://www.boe.es/buscar/act.php?id=BOE-A-1978-31229.

4 "Ley Orgánica 4/1979, de 18 de diciembre, de Estatuto de Autonomía de Cataluña," Agencia Estatal Boletín Oficial del Estado. Ministerio de la Presidencia, Relaciones con las Cortes y Memoria Democrática, accessed August 1, 2020, https://www.boe.es/buscar/doc.php?id=BOE-A-1979-30178.

5 "Referéndum sobre el proyecto de Estatuto de Autonomía para Cataluña," Constitución española. Congreso de los Diputados, accessed August 1, 2020, https://app.congreso.es/consti/elecciones/referendos/ref_cata_79.htm. 


\section{El proceso soberanista catalán}

La pérdida de poder de los nacionalistas de centro derecha de CiU - hasta entonces moderados - en las elecciones al Parlament de Cataluña de 2003, en favor de un tripartito de izquierdas formado por el Partit dels Socialistes de Catalunya (PSC), Esquerra Republicana de Cataluña (ERC) e Iniciativa per Catalunya Verds - Esquerra Unida i Alternativa (ICV-EUiA), bajo la presidencia del socialista Pasqual Maragall, que sería sustituido en 2006 por el también socialista José Montilla, marca un punto de inflexión en relación de Cataluña con el conjunto de España.

El Gobierno tripartito puso en marcha la elaboración de un nuevo Estatuto de Autonomía, para sustituir al aprobado en 1979, y acceder a un mayor nivel de autogobierno, dentro de un concepto de "España plural" que se adecuaría mejor a la realidad histórica y actual de Cataluña. El Parlament de Cataluña aprobó el nuevo Estatuto en septiembre de 2005 con una amplísima mayoría del 88,89\%, ${ }^{1}$ contando con la aprobación de CiU y con la única oposición del Partido Popular (PP), el partido principal de la derecha española. En ese momento el PP había perdido el poder en Madrid a favor del Partido Socialista Obrero Español (PSOE). Tal como establece la Constitución, el Estatuto tenía que ser después aprobado por las Cortes Generales (parlamento) españolas. Pero en ese trámite se introdujeron cambios importantes que rebajaban sustancialmente las ambiciones del texto aprobado en Cataluña. El nuevo texto, regresó en marzo de 2006, al Parlament, que lo volvió a aprobar, aunque en esta ocasión con una mayoría más exigua (71,85\%), ya que ERC consideró que los recortes que había sufrido en Madrid le habían desnaturalizado y votó en contra. En junio de 2006 el Estatuto fue sometido al referéndum de los ciudadanos de Cataluña y fue aprobado por un $73,2 \%$ de votos afirmativos, aunque con una participación de solo el 48,9\%. ${ }^{2}$ El Estatuto entró en vigor, pero el PP seguía oponiéndose y presentó un recurso de inconstitucionalidad ante el Tribunal Constitucional, sobre la mayor parte del nuevo Estatuto, primero directamente y luego a través de cinco Comunidades Autónomas en las que gobernaba.

La modificación por las Cortes Generales del Estatuto votado en primera instancia por el Parlament, produjo las primeras señales de ruptura política en Cataluña y supuso el principio de un cambio que se llamó después "proceso soberanista" y que llevaria a una gran parte de la clase política y de los ciudadanos catalanes a una deriva independentista en muy pocos años. Como hemos dicho, ERC fue el primer partido en desmarcarse del consenso general de los partidos catalanistas y rechazar el nuevo Estatuto. En febrero de 2006, mientras se estaba debatiendo en Madrid el texto del estatuto, se produjo en Barcelona la primera manifestación soberanista significativa para apoyar el "derecho a decidir" de la "nación catalana", a la que seguiría otra, en diciembre de 2007, ambas convocadas por la Plataforma por el Derecho a Decidir, y apoyadas por ERC. Paralelamente, se produjo un cambio en la posición de CiU, que pasó de ser autonomista a soberanista, impulsada por la necesidad de recuperar el poder, y también - según algunos analistas - por la necesidad de una huída hacia adelante debido a los casos de corrupción que estaban saliendo a la luz a raíz de su salida de las instituciones. Este cambio de CiU sería trascendental para el desarrollo del proceso, puesto que junto con ERC formaron un núcleo de una gran fuerza política y electoral.

El descontento, que estaba teniendo gran impacto en parte de la población catalana, se agravó definitivamente en junio de 2010 cuando el Tribunal Constitucional dictó sentencia sobre el recurso presentado por el PP, que introdujo nuevos recortes

1 "El Parlamento de Cataluña aprueba el nuevo Estatuto," El País, September 30, 2005, https://elpais.com/elpais/2005/09/30/actualidad/1128068217_850215.amp.html.

2 "Referéndum sobre reforma del Estatuto de Autonomia para Cataluña," Constitución española. Congreso de los Diputados, accessed August 1, 2020,

https://app.congreso.es/consti/elecciones/referendos/ref_cata_2006.htm. 
sobre lo ya aprobado por los catalanes en referéndum, hasta el punto de que casi todos los avances sobre el Estatuto de 1979 quedaban sin efecto. La sentencia produjo una crisis que dividió incluso al PSC, y supuso el final del Gobierno tripartito, y la mejora espectacular de las perspectivas electorales de CiU. En julio la organización Omnium Cultural convocó una manifestación con el lema "Somos una nación. Nosotros decidimos" a la que acudieron centenares de miles de personas, y en la que aparecieron banderas independentistas y se gritaron lemas a favor de la independencia.

CiU ganó las elecciones al Parlament en noviembre de 2010 y su nuevo líder, Artur Mas, fue investido Presidente de la Generalitat, aunque sin mayoría absoluta. Su proyecto principal, el denominado "pacto fiscal" que pretendía conseguir para Cataluña un sistema fiscal nuevo y más beneficioso - similar al que ya tenía el País Vasco, fracasó en julio de 2012 por el rechazo frontal del presidente del Gobierno español, que ya estaba en manos del PP. Este fracaso, junto a las declaraciones de varios municipios a favor de la independencia, y - sobre todo la multitudinaria manifestación del 11 de septiembre convocada por la denominada Asamblea Nacional de Cataluña con el lema "Cataluña, un nuevo Estado en Europa", contribuyeron a decantar definitivamente a CiU hacia la vía soberanista. En septiembre, el Parlament aprobó una moción en la que se pedía convocar una consulta sobre la independencia de Cataluña, que debería celebrarse en la siguiente legislatura, y en noviembre se celebraron elecciones anticipadas, que fueron ganadas de nuevo por $\mathrm{CiU}$, aunque lejos de las expectativas de conseguir mayoría absoluta, pues perdió 12 escaños. No obstante, llegó a un acuerdo de investidura con ERC, sobre la base de realizar la consulta de autodeterminación, y Artur Mas volvió a ser investido Presidente.

En enero de 2013 el Parlament aprueba la "Declaración de Soberanía y del derecho a decidir del Pueblo de Cataluña", que es suspendida por el Tribunal Constitucional cautelarmente en mayo y definitivamente en marzo de 2014. A pesar de la suspensión cautelar, en diciembre de 2013 el Presidente de la Generalidad anuncia la convocatoria de un referéndum el 9 de noviembre de 2014, incluyendo una pregunta con dos apartados: "¿Quiere que Cataluña sea un Estado?", "En caso afirmativo, ¿quiere que este Estado sea independiente?", y en septiembre de 2014 el Parlament aprueba una Ley de Consultas para amparar legalmente su celebración. ${ }^{2}$ El Tribunal Constitucional suspende cautelarmente tanto la Ley como el referéndum, que finalmente se convierte en un proceso de participación ciudadana sin carácter vinculante, en el que votan solamente un 37,02\% de los censados, de los cuales un $80,76 \%$ se declaran a favor de la independencia, y que no tiene ningún efecto político. ${ }^{3}$

Enenero de 2015 el Presidente Artur Mas anuncia para el mes de septiembre un adelanto de las elecciones al Parlament, que en esta ocasión se entenderían como un plebiscito sobre la independencia de Cataluña, comprometiéndose a declarar la independencia en un plazo de 18 meses si los partidos soberanistas ganaban las elecciones. La coalición entre Convergencia y Unión se rompe por la negativa de este último partido a secundar la vía unilateral a la independencia, y Convergencia cierra un acuerdo con ERC para presentarse juntos a las elecciones bajo las siglas Junts pel Si, coalición que finalmente ganaría las elecciones, pero

1 "Resolución 5/X del Parlamento de Cataluña, por la que se aprueba la Declaración de soberanía y del derecho a decidir del pueblo de Cataluña," Parlamento de Cataluña, accessed August 1, 2020, https://www.parlament.cat/document/intrade/7217.

2 "Ley 10/2014, de 26 de septiembre, de consultas populares no referendarias y otras formas de participación ciudadana," Agencia Estatal Boletín Oficial del Estado. Ministerio de la Presidencia, Relaciones con las Cortes y Memoria Democrática, accessed August 1, 2020, https://www.boe.es/buscar/pdf/2015/BOE-A-2015-2743-consolidado.pdf.

3 "Resultados del proceso participativo," Generalitat de Cataluña, accessed August 1, 2020, http://www.participa2014.cat/resultats/dades/es/escr-tot.html;

"1,8 millones de personas votan por la independencia catalana en el 9-N," El País, November 10, 2014, https://elpais.com/politica/2014/11/09/actualidad/1415542400_466311.html. 
sin mayoría absoluta. La necesidad de apoyo del otro partido independentista, Candidatura de Unidad Popular (además - CUP), un partido de izquierdas que no aceptaba a Artur Mas por sus posibles relaciones con prácticas corruptas de la antigua Convergencia, obligan a éste a ceder la presidencia a favor de Carles Puigdemont. Aunque Junts pel Si y CUP tenían en conjunto la mayoría absoluta del Parlament (72/135), debido un sistema electoral que prima el voto rural sobre el urbano, no alcanzaron el 50\% del voto emitido, sino el $47,8 \%,{ }^{1}$ lo que llevo al candidato de CUP a declarar que el plebiscito se había perdido como tal, a pesar de lo cual el proyecto soberanista siguió su curso basándose en la mayoría parlamentaria independentista, que aprobó en noviembre una resolución en la que se declaraba solemnemente el inicio del proceso de creación del Estado catalán independiente en forma de república.

El Tribunal Constitucional suspendió esta resolución cautelarmente en noviembre y definitivamente en diciembre, lo que no impidió que el Parlament siguiera con sus planes. En octubre de 2016 aprobó una resolución en la cual se instaba al Gobierno catalán a celebrar un referéndum vinculante sobre la independencia de Cataluña, a más tardar, en septiembre de 2017. En junio de 2017 el Presidente Puigdemont anunció que el referéndum se celebraría el 1 de octubre, y que en la papeleta de voto aparecería la pregunta: "¿Quiere que Cataluña sea un Estado independiente en forma de república? Sí o No" Entre el 6 y el 8 de septiembre la mayoría independentista del Parlament aprobó dos leyes que señalaban la ruptura definitiva con el marco jurídico de la Constitución y el Estatuto: la denominada "Ley del referéndum de autodeterminación vinculante sobre la independencia de Cataluña", que regulaba las normas de celebración de la consulta incluyendo la creación de la Sindicatura Electoral de Cataluña, en la que se declaraba que el pueblo de Cataluña es un sujeto político soberano y como tal ejerce el derecho a decidir libre y democráticamente su condición política y establecía que la independencia se proclamaría dos días después de la publicación de los resultados oficiales si el "si" obtenía más votos que el "no", sin requerir una participación mínima. ${ }^{2}$

El Tribunal Constitucional suspendió cautelarmente la aplicación de la ley el 7 de septiembre y definitivamente el 17 de octubre, al entender que la norma invadía competencias estatales y vulneraba la supremacia de la Constitución, la indisoluble unidad de la Nación española y la soberanía nacional. La segunda fue la llamada "Ley de transitoriedad jurídica y fundacional de la República Catalana", cuya finalidad era garantizar la seguridad jurídica, así como la sucesión ordenada de las administraciones y la continuidad de los servicios públicos, durante el proceso de transición de Cataluña hacia el estado independiente de la República de Cataluña. En su artículo 1 declaraba que "Cataluña se constituye en una República de derecho, democrática y social". ${ }^{3} E l 12$ de septiembre, el Tribunal Constitucional acordó también la suspensión de esta ley. La votación de ambas leyes, que rompian definitivamente con la legalidad española, se hizo por procedimientos extraordinarios, sin respetar los derechos de las minorías parlamentarias. Los letrados del Parlament advirtieron antes de su aprobación que el Parlament no tenía competencias para aprobarlas y el Consejo de Garantías estatutarias advirtió de que no se había pedido el preceptivo informe antes de su discusión. Además en ninguna votación se alcanzó la mayoría de 2/3 requerida por el propio Estatuto para su modificación.

Finalmente, el 1 de octubre se celebró el referéndum, a pesar de estar suspendido por el Tribunal Constitucional y de las advertencias del gobierno central. La Guardia Civil y

1 "Los independentistas ganan las elecciones y pierden su plebiscito," El País, September 28, 2015, https://elpais.com/ccaa/2015/09/27/catalunya/1443387513_045607.html.

2 "LEY 19/2017, de 6 de septiembre, del referèndum de autodeterminación," Diari Oficial de la Generalitat de Catalunya, accessed August 1, 2020, http://portaldogc.gencat.cat/utilsEADOP/PDF/7449A/1633376.pdf.

3 "LEY 20/2017, de 8 de septiembre, de transitoriedad jurídica y fundacional de la República," Diari Oficial de la Generalitat de Catalunya, accessed August 1, 2020, https://www.boe.es/ccaa/dogc/2017/7451/f00001-00027.pdf. 
la Policía Nacional intervinieron para impedir la votación y entraron en unos 400 colegios electorales, que teóricamente correspondian a un $14,4 \%$ del censo. ${ }^{1}$ Hubo episodios de violencia por ambas partes, ampliamente difundidos. Según el Gobierno catalán 893 civiles fueron atendidos por el Sistema de Emergencias Médicas de Cataluña, aunque el juez que investigó el caso por la denuncia presentada por la Generalidad estableció en 130 el número de heridos por las cargas policiales. ${ }^{2}$ En el otro lado, según el Ministerio del Interior, 431 agentes de la Policía Nacional y la Guardia Civil resultaron heridos. ${ }^{3}$

La votación no tuvo las mínimas garantías de limpieza, ni de control ya que todos los miembros de la Sindicatura Electoral de Cataluña, que era teóricamente la encargada de garantizar su cumplimiento, habían dimitido. Apenas 45 minutos antes de comenzar, se cambiaron las normas incluyendo un censo universal (tampoco había ninguna garantía de que el censo fuera correcto) permitiendo a cualquier ciudadano votar en cualquier centro, además de aceptarse papeletas caseras y votos sin sobre. En consecuencia, se registraron, documentadas en videos, casos de ciudadanos votando más de una vez en diferentes centros, votos de extranjeros no incluidos en el censo, e incluso de niños. También se detectó el transporte de urnas sin precintar conteniendo votos en su interior, así como urnas en la calle en las que cualquier ciudadano sin control censal podía depositar los votos que quisiera. ${ }^{4}$

El recuento adoleció de la misma falta de garantías, ya que no existían interventores de los partidos no independentistas ni existió un órgano independiente que lo controlara. Los resultados oficiales de la Generalitat no se conocieron hasta el 6 de octubre y eran muy diferentes de los provisionales que se difundieron el día de la votación. Según estos resultados, la participación fue del $43,03 \%$, con un $90,18 \%$ de votos afirmativos, que corresponderían a 2.044.038 personas, ${ }^{5}$ una cifra similar al número de votos que obtuvieron los paridos independentistas en las elecciones de 2015 y 2017. Los observadores internacionales, que habían sido llamados por la Generalitat, consideraron que la ley que posibilitaba el referéndum no cumplió una serie de buenas prácticas, y que el referéndum no pudo cumplir los estándares internacionales debido a las circunstancias adversas en que tuvo lugar. ${ }^{6}$

El 10 de octubre, el Presidente Puigdemont declaró la independencia de Cataluña aunque suspendió inmediatamente sus efectos "para emprender un diálogo para llegar a una solución acordada para avanzar en las demandas del pueblo de Cataluña". 7 Al día siguiente, el Gobierno central hizo un requerimiento al Presidente para que aclarase si efectivamente había declarado la independencia, como paso previo para la aplicación del artículo 155 de la Constitución, que prevé - del mismo modo que otras constituciones de carácter federal, como la alemana - la intervención estatal "Si una Comunidad Autónoma no cumpliere las obligaciones que la Constitución u otras leyes le impongan, o actuare de

1 Ortigosa 2018, 373.

2 "¿Cuántos heridos hubo en realidad el 1-O?," El País, October 3, 2017, https://elpais.com/elpais/2017/10/02/hechos/1506963876_226068.html.

3 Marisa Recuero, Carol Álvarez, and David Lema. "Desafio por la independencia de Cataluña, en vivo: la Justicia 'contabiliza' 130 heridos por el 1-O," El Mundo, October 6, 2017, https://www.elmundo.es/cataluna/2017/10/06/59d7246c46163f201f8b45d6.html.

4 "Irregularidades en el referéndum: gente que vota cuatro veces, votos 'extranjeros'...," El Confidencial, October 1, 2017, https://www.elconfidencial.com/espana/ cataluna/2017-10-01/irregularidades-votaciones-referendum-cataluna_1453255/.

5 "Referèndum d'autodeterminació de Catalunya. Resultats definitius," Generalitat de Cataluña, accessed August 1, 2020, http://estaticos.elperiodico.com/resources/pdf/4/3/1507302086634.pdf.

6 Jordi Pérez Colomé. "La misión de observadores concluye que el referéndum no cumple los "estándares internacionales"," El País, October 3, 2017,

https://elpais.com/politica/2017/10/03/actualidad/1507046129_416345.html.

7 "Así ha sido la declaración de independencia de Puigdemont," El País, October 10, 2017, https://elpais.com/elpais/2017/10/10/videos/1507658219_177463.html. 
forma que atente gravemente al interés general de España."1 El 27 de octubre el Parlament aprobó la Declaración Unilateral de Independencia (DUI)² en una votación claramente ilegal, y ese mismo día el Gobierno central aplicó el Artículo 155, cesó al Gobierno catalán, disolvió el Parlamento, asumió todas las competencias autonómicas y convocó elecciones para el día 21 de diciembre. Ningún Estado del mundo ni ninguna organización internacional reconoció la declaración de independencia de Cataluña.

Muchos de los líderes independentistas, incluida la mayor parte del Gobierno de la Generalitat, así como los líderes de las organizaciones soberanistas Asamblea Nacional de Cataluña y Omnium Cultural fueron encarcelados, acusados de rebelión y otros delitos, mientras que el Presidente Puigdemont y otros seis huyeron de la justicia española y encontraron refugio en otros países europeos. El juicio de los 12 principales acusados tuvo lugar en el Tribunal Supremo en los primeros meses de 2019. La sentencia, que se conoció el 14 de octubre de ese año, condenó a penas que iban desde el pago de multas y la inhabilitación para tres de ellos a penas de cárcel de entre nueve y trece años para los otros nueve, por delitos de sedición, malversación de fondos públicos, y desobediencia Actualmente cumplen condena en cárceles catalanas controladas por la Generalitat de Cataluña, que tiene transferidas las competencias de prisiones, y ya han tenido algunos permisos para salir a trabajar o cuidar a familiares que han sido recientemente revocados por el Tribunal Supremo.

La condena a los líderes del proceso soberanista - aunque esperada - creó una gran conmoción en Cataluña, y no solo en los sectores independentistas. El 14 de octubre el Aeropuerto de Barcelona fue ocupado por miles de manifestantes independentistas, provocando la cancelación de 108 vuelos. En Gerona grupos de manifestantes cortaron las vías del tren de alta velocidad, en otros lugares fueron cortadas las carreteras. Los disturbios duraron cinco días, en los que 579 civiles y 288 agentes de policía resultaron heridos. Fueron detenidas 194 personas de las que 28 ingresaron en prisión provisional. ${ }^{3}$

El independentismo ha utilizado a los presos como bandera y ejemplo de la falta de democracia del Estado español, presentándolos tanto en Cataluña como en el resto de Europa y del mundo como presos políticos que estarian en prisión por sus ideas. Esto es completamente falso como lo demuestra el mismo hecho de que los que denuncian esa situación puedan hacerlo sin tener ningún problema por ello. En Cataluña hay una parte muy importante de la población que profesa ideas independentistas, incluido el propio Gobierno catalán actual encabezado por su último presidente (recientemente inhabilitado por desobediencia a la Junta Electoral), y no son perseguidos por ello. Los políticos condenados por el Tribunal Supremo no lo han sido por defender sus ideas, a lo que tienen derecho, sino por cometer delitos tipificados en el Código Penal, que fue aprobado democráticamente, y contra la Constitución, que fue refrendada masivamente, incluso en Cataluña, por los ciudadanos. España es uno de los países más libres del mundo. En el Índice de Democracia que publica anualmente The Economist, España aparece (2019) en el puesto 16 entre los únicos 22 países del mundo que se consideran democracias completas. ${ }^{4}$

Muchos analistas, incluso no independentistas, han acusado al gobierno español entonces del PP - de judicializar un conflicto que debía haberse tratado en el ámbito político. Desde luego, el Gobierno del PP fue pasivo ante el deterioro de la situación y podía

1 "Constitución Española," Agencia Estatal Boletín Oficial del Estado, accessed August 1, 2020, https://www.boe.es/eli/es/c/1978/12/27/(1)/con.

2 "Declaració dels representants de Catalunya," Ara, accessed August 1, 2020, https://www.ara.cat/2017/10/10/Declaracio_Independencia_amb_logo_-1.pdf.

3 "Casi 600 heridos, 200 detenciones, daños... Las cifras de una semana de disturbios," La Vanguardia, October 20, 2019, https://www.lavanguardia.com/ politica/20191020/471095242135/cataluna-disturbios-detenidos-policia-heridos-barcelona.html. 
haber tomado iniciativas políticas, que no tomó, para intentar reconducir la situación. Pero los culpables de que el asunto se judicializara no fueron las instituciones españolas, sino aquellos que hicieron caso omiso de las decisiones del Tribunal Constitucional y vulneraron consciente y reiteradamente las leyes.

No obstante, el sentimiento de agravio revitalizó el independentismo, a pesar de la decepción de la fallida DUI, y en las elecciones del 21 de diciembre de 2017, los tres partidos independentistas volvieron a conseguir en conjunto la mayoría en el Parlament, aunque el partido más votado fue Ciudadanos, opuesto frontalmente a la independencia. En esta ocasión, los sucesores de Convergencia - bajo las siglas Junts per Catalunya (además JxC) - y ERC se presentaron por separado. Junto con la CUP obtuvieron 70 diputados, dos menos que en 2015, y un total del 47,5\% de los votos emitidos, tres décimas menos que en la elección anterior. ${ }^{1}$ Joaquim Torra, un activista independentista próximo a Puigdemont quien ha seguido dirigiendo la política catalana desde Bruselas, - fue elegido Presidente de la Generalitat, restaurándose así las instituciones y competencias que la aplicación del artículo 155 había suspendido.

En junio de 2018, ERC votó a favor de la moción de censura que dio por terminado el Gobierno del PP en Madrid, a favor de Pedro Sánchez, líder del PSOE, y en enero de 2020 facilitó, absteniéndose, la investidura del mismo Sánchez al frente de un Gobierno de coalición con la formación izquierdista Unidas Podemos, a cambio de la constitución de una mesa de diálogo bilateral entre el Gobierno de España y el de Cataluña para tratar el contencioso en todos sus aspectos, a lo que el Gobierno actual se ha mostrado favorable. Esta posición ha supuesto una causa de división con el otro gran partido independentista, JxC, que votó en contra de la investidura. De hecho ambos partidos, están cada vez más enfrentados entre sí, ya que compiten por ser el principal partido soberanista catalán, y el Gobierno catalán - que comparten - se sostiene a duras penas debido a esa división. A finales de enero, el Presidente Torra dio por finalizada la legislatura y anunció que convocaría elecciones una vez que los presupuestos anuales fueran aprobados. La crisis de la pandemia Covid19 ha paralizado por el momento ésta y cualquier otra iniciativa política. Pero el Presidente Torra fue condenado en diciembre de 2019 a una inhabilitación de un año y medio por el Tribunal Superior de Justicia de Cataluña, por desobedecer la orden de retirar símbolos partidistas de los edificios públicos en período electoral. El Tribunal Supremo ha ratificado esta sentencia en septiembre de 2020, y las nuevas elecciones están previstas para el 14 de febrero.

\section{Las causas y razones del intento de secesión}

Aunque el proceso soberanista catalán también ha perjudicado a España en su conjunto, especialmente en su imagen exterior, lo cierto es que para Cataluña ha sido un desastre sin paliativos. Los independentistas no han conseguido ninguno de sus objetivos, y probablemente ahora están más lejos de conseguirlos que antes de empezar el proceso. En lugar de conseguir la independencia, perdieron su autogobierno, como en 1714 y en 1934, aunque en este caso por un período de tiempo muy breve. Han agudizado la división interna en Cataluña, y el recelo - cuando no la enemistad - en buena parte de España. Se ha puesto de manifiesto el nulo apoyo internacional con el que contaban, y las falsedades que habian dicho al respecto. Muchos de sus dirigentes políticos están encarcelados o huidos de la justicia. Y Cataluña ha sufrido un duro golpe económico, con la salida de muchas empresas, y un deterioro de su imagen internacional que no será fácil revertir. 
Mucho se ha debatido sobre las razones por las que se ha producido ahora este movimiento secesionista con tanta fuerza, en una región que lleva más de 500 años formando parte de España (y mucho antes aún, unida a otras regiones españolas), cuando gozaba de más autogobierno que nunca antes en su historia, y de un gran progreso económico, social y cultural.

Sin duda, el primer elemento a considerar es una cierta contante histórica de oposición a la hegemonía del poder central, radicado primero en Castilla y luego en la capital, Madrid, que se ha manifestado, como hemos visto antes, en sucesivos episodios de crisis a lo largo de varios siglos. En todos estos episodios los intentos separatistas, u hostiles a Castilla, de los secesionistas catalanes salieron derrotados, pero esas derrotas son consideradas por muchos de ellos más que como fracasos como hechos gloriosos. Baste decir, que la fiesta nacional catalana no conmemora una victoria, como suele suceder en la mayoría de los países, sino una derrota: la toma de Barcelona el 11 de septiembre de 1714 por las tropas del rey Felipe V. Las decepciones anteriores no obstan para que el intento de secesión se reitere en cada ocasión en que el poder central parece débil o proclive a ceder.

En este caso concreto, el desgraciado recorrido del Estatuto de 2006, sometido a sucesivos recortes incluso después de haber sido aprobado en referéndum, contribuyó sin duda al malestar de una parte importante de la población de Cataluña. Además, la gran recesión que afectó muy duramente a España a partir de 2008, y sobre todo en 2012, fue también una causa importante de desafección. Los dirigentes políticos catalanes, intentaron eludir su inevitable responsabilidad en el deterioro económico y en las medidas de austeridad, echando la culpa a la pertenencia de Cataluña a España. Los círculos independentistas vieron en ambas causas de descontento una oportunidad única de impulsar el proceso soberanista, sobre todo cuando constataron el entusiasmo de una importante parte de la población, expresado en las sucesivas manifestaciones del 11 de septiembre. Un entusiasmo que finalmente les arrastró a ellos a tomar decisiones que sabian perfectamente que no tenian ninguna viabilidad. En los movimientos sociales, encender un fuego suele resultar - en determinadas circunstancias - muy fácil, pero controlarlo nunca lo es tanto.

Conviene, además, señalar que las doctrinas nacionalistas de finales del siglo XIX a las que nos hemos referido como origen del nacionalismo catalán moderno, contienen un cierto matiz etnicista o supremacista. No es casual que los países europeos que se unificaron en esa época, basándose en esas mismas doctrinas, Italia y Alemania, fueran los dos en los que triunfó el fascismo. Los nacionalismos vasco y catalán no fueron tampoco ajenos a estas tendencias. Sabino Arana, fundador del Partido Nacionalista Vasco, era abiertamente supremacista, y en Cataluña hubo también personajes como Josep Dencàs, que llego a ser Consejero de Gobernación de la Generalitat o los hermanos Badía, que formaron parte de Estat Catalá, que tuvieron claras influencias fascistas, e incluso contactos con el fascismo italiano. Es muy difícil que exista un nacionalismo que no contenga alguna dosis de supremacismo, aunque siempre trate de ocultarlo. "Somos diferentes" quiere decir, en muchas ocasiones, "somos mejores".

El sentimiento identitario, de pueblo diferente - y maltratado - que pervive en una parte de la población con sólidas raíces catalanas, es el primer fundamento de la ideología independentista. El mundo rural catalán, en el que los partidos independentistas obtienen en cada elección mayorías, a veces abrumadoras, siente amenazada su identidad, su lengua, sus costumbres, por gente venida de fuera, del sur, a los que no consideran sus 
iguales. Hay un cierto reflejo en el relato independentista de lo que en Europa se llama "riesgo moral" cuando se trata de ayudar económicamente a regiones más pobres: nosotros trabajamos para ellos, que son vagos y viven a nuestra costa. En todos los casos se refieren básicamente al sur. El sentimiento de agravio, de estar perjudicados por su pertenencia a España, o no ser suficientemente respetados ha sido profusamente utilizado para animar el proceso soberanista.

Ello nos lleva al otro argumento del independentismo: el económico. Cuando el lema de "Un nuevo Estado en Europa" se agotó ante la evidencia de que eso no era posible, se pasó rápidamente a "España nos roba", un mensaje demoledor porque puede seducir incluso a aquéllos que no han nacido en Cataluña o proceden de familias de otras partes de España, a los que se intenta convencer de que en una Cataluña independiente su nivel de vida sería muy superior, porque no habría que "cargar" con regiones mucho más pobres como Andalucía o Extremadura, aunque en ocasiones sean sus propias regiones de origen. Naturalmente no se dice que, como sucede en Europa, las regiones más ricas siempre ayudan a las más pobres a favor de una cohesión necesaria para progresar juntos, ni que en gran parte la prosperidad relativa de Cataluña se debe a las facilidades que ha tenido en el mercado interior y a la fuerza de trabajo barata que ha obtenido de otras partes de España. Se presenta un país cuyo desarrollo le permitiría estar a la altura de Dinamarca, pero que está lastrado por su pertenencia a un Estado atrasado e ineficaz que se lo impide. Es significativo que partidos teóricamente de izquierdas como ERC o CUP, que se sitúan en el bando independentista, no hablan de solidaridad con el resto de España, o en todo caso la subordinan a la consecución de la independencia. Este argumento ha decaído sensiblemente después de que haya sido rebatido con cifras y hechos, ${ }^{1}$ y hayan salido a la luz numerosos episodios de corrupción que afectan al partido que ha dirigido durante décadas el nacionalismo catalán, Convergencia Democrática de Cataluña y a su líder histórico, Jordi Pujol, con lo que muchos catalanes se han dado cuenta de que quien realmente les roba no es España sino sus propias instituciones.

Finalmente, no conviene desdeñar el papel que ha jugado en este proceso el interés de ciertas clases políticas y empresariales catalanas que han decidido que sin las ataduras del poder central podrían ejercer mejor a su antojo todo el poder en su tierra y, por supuesto, obtener ventajas de ello. A pesar de que, como veremos más adelante, una mayoría de los catalanes actuales tienen su origen fuera de Cataluña, y su apellido es castellano, de los 70 diputados de partidos independentistas (JxC, ERC, CUP) que tiene actualmente el Parlament, solo nueve $(12,8 \%)$ tienen un primer apellido castellano. ${ }^{2}$ Es decir, los dirigentes tienen en su mayoría raíces genuinamente catalanas - y defienden un Estado propio que favorecería sus intereses - aunque tengan muchos seguidores cuyo origen se sitúa en otras partes de España, que apoyan el proceso bien sea por un concepto romántico - los más jóvenes - al que se adhieren aunque no sea propiamente el suyo, o por un cálculo de que ese nuevo Estado mejorará su nivel de vida.

\section{El derecho a decidir}

Los partidos y organizaciones separatistas han centrado su discurso en lo que han denominado "derecho a decidir" que sería el fundamento para poder convocar un referéndum de autodeterminación vinculante, con la esperanza de que en él no participaría la mayoría de la población contraria a la independencia, como ha sucedido en las consultas ilegales 
celebradas hasta ahora, lo que les daría una mayoría que, por exigua que fuese, serviría hacer valer su reivindicación, sobre todo en la arena internacional.

Además, centrando la cuestión en el acto de decidir en sí, se elude hábilmente la discusión sobre cuales serian las consecuencias de una ruptura con España si ésta finalmente se produjera, incluida la salida de la Unión Europea, que es una cuestión de la que prácticamente no se ha hablado durante todo el proceso. Finalmente, es mucho más sencillo obtener una aprobación mayoritaria de una cuestión aparentemente tan atractiva como la capacidad de decidir, y de hecho en este tema los secesionistas hacen presunción de unas mayorías favorables que rondarían el $80 \%$, mientras que como hemos visto los votos independentistas nunca han llegado al 50\%. Efectivamente, en la primera oleada 2020 del barómetro de opinión política que elabora y publica el Centre d'Estudis d'Opinió (CEO) dependiente de la Generalitat de Catalunya, ${ }^{1}$ cuando se plantea la cuestión de si los catalanes y catalanas tienen derecho a decidir su futuro como país votando en un referéndum, un $78,4 \%$ dicen estar muy de acuerdo o bastante de acuerdo. Nótese que en la pregunta no se menciona la palabra autodeterminación, ni mucho menos independencia. Planteado así, ¿quién puede estar en desacuerdo con la posibilidad de decidir su futuro, personal o colectivo? Si no se especifica más, lo raro es que no la aprueben el 100\% de los consultados.

Pero una cosa es el derecho a decidir, que los catalanes ejercen cada vez que van a votar, incluso en referéndums cuando se trata de aprobar la Constitución o el Estatuto de Autonomía, y otra muy distinta el derecho de autodeterminación, que implica a su vez un reconocimiento de soberanía, y un derecho de secesión. Ninguna Constitución del mundo reconoce el derecho a la autodeterminación, a excepción de Liechtenstein, Etiopía y del estado caribeño formado por las islas de San Cristóbal y Nieves. Ni siquiera Escocia, que fue un Estado independiente hasta 1707 fecha en la que se firmó el Acta de Unión con Inglaterra ${ }^{2}$ para crear el Reino de Gran Bretaña, y donde no existe una Constitución escrita, tiene reconocido ese derecho, ya que fue el Parlamento británico de Westminster el que transfirió expresamente al Parlamento escocés la facultad de convocar el referéndum que se celebró en septiembre de 2014. Tampoco es aplicable el caso de Quebec cuya relación con Canadá fue definida a partir de 1867,3 por una serie de leyes conocidas como el Acta de la Norteamérica Británica, y que nunca aprobó el Acta Constitucional de 1982, ${ }^{4}$ por la que Canadá pasaba a ser completamente independiente, a pesar de lo cual tanto el referéndum de 1980 como el de 1995 ofrecian a los votantes un nuevo marco de asociación con Canadá, y el Tribunal Supremo canadiense determinó que una declaración unilateral de independencia no sería legal.

En lo que respecta a la Constitución Española, dice en su artículo 1, apartado 2 que "La soberanía nacional reside en el pueblo español, del que emanan los poderes del Estado," ${ }^{5}$ y esto se refiere a todo el territorio del Estado. En consecuencia, los catalanes tienen derecho a decidir sobre el futuro de Cataluña - y de toda España - pero no solo ellos, es un derecho que comparten con el resto de los españoles. Limitar el derecho a decidir sobre el futuro político de Cataluña a los que viven actualmente en Cataluña privaría al resto de españoles de este derecho que la Constitución consagra. La Constitución puede ser

1 "Baròmetre d'Opinió Política. $1^{a}$ onada 2020. Taules estadístiques," Centre d'Estudis d'Opinió. Generalitat de Cataluña, accessed August 1, 2020, http://upceo.ceo.gencat.cat/ wsceop/7548/Taules\%20estad\%C3\%ADstiques\%20-962.pdf. P. 67.

2 "Union with England Act 1707," The National Archives, accessed August 1, 2020, https://www.legislation.gov.uk/aosp/1707/7/contents.

3 "Constitution Act, 1867," Justice Laws Website. Government of Canada, accessed August 1, 2020, https://laws-lois.justice.gc.ca/eng/Const/page-1.html.

4 "Canada Act 1982," The National Archives, accessed August 1, 2020, https://www.legislation.gov.uk/ukpga/1982/11/contents/enacted. https://www.boe.es/legislacion/documentos/ConstitucionCASTELLANO.pdf. 
modificada, pero al estar tanto este Artículo, como el número 2, que consagra la indisoluble unidad de la nación española incluidos en el Titulo Preliminar, la reforma tendría que seguir el camino más difícil, descrito en el Artículo 168, que desembocaría en un referéndum en toda España, con lo que las posibilidades de que esa modificación recoja el derecho a la secesión de una parte del territorio son prácticamente nulas.

Ante la imposibilidad de encontrar un resquicio legal en España en el que basar el derecho de autodeterminación, los secesionistas han intentado buscarlo en el derecho internacional. Pero la doctrina de Naciones Unidas, reiteradamente definida por esta organización, indica que éste es un derecho aplicable exclusivamente a los pueblos coloniales o sometidos a dominación extranjera. El derecho de autodeterminación se define, en la Resolución 1514, de 1960, como el derecho a la independencia de los pueblos sujetos a una subyugación, dominación y explotación extranjeras. De hecho el punto 6 de esta resolución establece que "todo intento encaminado a quebrantar total o parcialmente la unidad nacional y la integridad territorial de un país es incompatible con los propósitos y principios de la Carta de las Naciones Unidas. ${ }^{" 1}$ La resolución 2625, de 1970, que también aborda el tema de la autodeterminación de territorios coloniales, señala en su articulado que no debe interpretarse "en el sentido de que autoriza o fomenta cualquier acción encaminada a quebrantar o menospreciar, total o parcialmente, la integridad territorial de Estados soberanos e independientes ... dotados de un gobierno que representa a la totalidad del pueblo perteneciente al territorio, sin distinción por motivo de raza, credo o color." ${ }^{2}$

Cataluña no tiene ningún título o fundamento, ni histórico ni político, en el que basar su derecho de autodeterminación, excepto la pretendida voluntad de su población, discutible como hemos visto porque solo se pregunta por un genérico "derecho a decidir" sin especificar las consecuencias. En todo caso, si este argumento se aceptase permitiría que cualquier territorio en cualquier parte del mundo pudiera apelar al derecho de autodeterminación siempre que su población estuviera a favor, aunque fuera coyunturalmente y por motivos circunstanciales o egoístas, por ejemplo porque se hubieran descubierto ciertos recursos. Y también - por supuesto - que una parte de Cataluña exigiera también su propio derecho a autodeterminarse y a separarse del resto, e incluso dentro de ésta parte, aún una más pequeña podría intentar hacer lo mismo.

La reivindicación independentista se ha querido fundamentar - sobre todo en el exterior donde existe un escaso conocimiento de la situación real - en la existencia de un "pueblo" catalán que sería depositario de una soberanía propia, arrebatada por España en algún momento. Como hemos visto en el repaso histórico, esa soberanía no ha existido nunca, aunque Cataluña haya tenido instituciones, fueros y leyes propias, como las tuvieron también el País Vasco, Valencia, Mallorca, Castilla, León, y la mayoría de los territorios hispanos. Además, el lema "Cataluña, un solo pueblo" acuñado por el político nacionalista Josep Benet y adoptado con entusiasmo por Jordi Pujol, es completamente irreal. Después de tantos siglos de convivencia no es posible hablar de un demos propiamente catalán en el que residiría la soberanía que se reivindica. El barómetro del CEO al que nos henos referido, ${ }^{3}$ constata que hay una mayoría de más de diez puntos porcentuales $(50,7 \%$ frente a $40,6 \%$ ) de ciudadanos catalanes actuales cuyo padre ha nacido fuera de Cataluña. Lo mismo sucede con las madres, aunque en

1 "Declaration 1514 on the granting of independence to colonial countries and peoples," United Nations Documents, accessed August 1, 2020, http://undocs.org/A/RES/1514(XV).

2 "Declaration 2625 on Principles of International Law Concerning Friendly Relations and Cooperation Among States in Accordance with the Charter of the United States," United Nations Documents, accessed August 1, 2020, https:// www.undocs.org/A/RES/2625(XXV).

3 "Baròmetre d'Opinió Política. 1" onada 2020," Centre d'Estudis d'Opinió. Generalitat de Cataluña, accessed August 1, 2020,

http://upceo.ceo.gencat.cat/wsceop/7548/Taules\%20estad\%C3\%ADstiques\%20-962.pdf. P. 47. 
este caso la diferencia es menor, $47,9 \%$ nacidas fuera frente a $44 \%$ nacidas en Cataluña, tal vez como consecuencia de que algunos trabajadores inmigrantes encontraron esposa en Cataluña. Esto significa que la mayoría de los habitantes actuales de Cataluña no son hijos de catalanes. Incluso un $23,9 \%$ han nacido ellos mismos en otras partes de España y un $7,2 \%$ en otro país. El $55 \%$ de los actuales habitantes de Cataluña no tienen ningún abuelo catalán. Solo el $18,4 \%$ tiene los cuatro abuelos catalanes. Según el Instituto de Estadística de Cataluña los 20 apellidos más frecuentes de la población catalana son castellanos. ${ }^{1}$ Cuando se pregunta qué lengua considera como propia (pregunta 67), un 44,5\% responde que el castellano frente a un $41,3 \%$ que señalan al catalán, y los dos por igual el $12,8 \%$. Esto después de 30 años de inmersión lingüística (toda la enseñanza se realiza en catalán excepto dos horas semanales de castellano) porque cuando se pregunta qué idioma hablaba de pequeño en su casa (pregunta 68), el castellano sube hasta el 57,1\%, más de 20 puntos por encima del catalán, 35,4\% (ambos el 4,3\%). Hablar en este escenario de un solo pueblo catalán parece cuando menos utópico. ${ }^{2}$

Por supuesto no se puede hacer ninguna discriminación entre catalanes viejos y nuevos, pero cuando se aduce una soberania originaria y antigua, hay que saber a quién nos estamos refiriendo. Para votar en Cataluña solo hace falta estar empadronado en un municipio catalán dos meses antes de la votación. Es decir, una persona que haya llegado hace tres meses de Jaén a trabajar en Barcelona, donde se ha empadronado, tendría derecho decidir sobre el futuro político de Cataluña, mientras que sus hermanos, que no se han movido de su ciudad de origen, no pueden hacerlo, por supuesto. Y tampoco pueden hacerlo los millones de españoles de origen catalán - o incluso nacidos en Cataluña - que por razones laborales, familiares o de otra índole están empadronados en otras partes de España fuera de Cataluña.

\section{La dimensión política de la cuestión}

Los secesionistas intentan plantear el proceso soberanista catalán como la pugna de un pueblo unido, el catalán, contra la opresión española. Pero está muy lejos de la realidad. De hecho, el único consenso mayoritario entre los catalanes es el que se refiere a la opinión de que Cataluña goza actualmente de una autonomía insuficiente. El barómetro del CEO al que venimos haciendo referencia, cuando se pregunta a los ciudadanos catalanes si creen que Cataluña goza de suficiente autonomía (pregunta 32), un 63\% de los encuestados creen que es insuficiente, más del doble de los que creen que es suficiente o demasiada $(29,6 \%){ }^{3}$

Pero cuando se pregunta sobre lo que creen que Cataluña debería ser en el futuro (pregunta 33), ${ }^{4}$ solo un $35,5 \%$ de los encuestados se declaran por un Estado independiente, mientras que un 33,3\% prefieren que sea una región o una autonomía española, y un 23,9\% optar por un Estado dentro de una España federal. Nótese que existe casi una simetría entre los partidarios de la independencia y los que optan por mantener el statu quo actual, alrededor de una tercera parte de la población en cada posición, mientras que un sector importante de los encuestados (casi una cuarta parte) se encuentra en una posición intermedia y podría inclinar la balanza hacia un lado u

1 "Apellidos más frecuentes de la población. 2018," Instituto de Estadistica de Cataluña. Generalitat de Cataluña, accessed August 1, 2020, https://www.idescat.cat/pub/?id=aec\&n=948\&lang=es.

2 "Baròmetre d'Opinió Política. 19 onada 2020," Centre d'Estudis d'Opinió. Generalitat de Cataluña, accessed August 1, 2020,

http://upceo.ceo.gencat.cat/wsceop/7548/Taules\%20estad\%C3\%ADstiques\%20-962.pdf. P. 93. 
otro. Parece evidente a la vista de estas cifras, que una pregunta binaria como la que se planteó el 1 de octubre de 2017, independencia sí o no, deja a este último sector entre dos fuegos, sin una posibilidad de ejercer su opción de futuro, que no es ni la independencia ni el mantenimiento de la actual situación. Se está forzando a una parte sustancial de la población a elegir entre dos posibilidades, ninguna de las cuales desea, o a abstenerse, privando a la consulta de la legitimidad imprescindible en una decisión de este calado histórico. De hecho, cuando en el barómetro la pregunta se hace directamente en forma binaria, sin otra alternativa, (pregunta 34$)^{1}$ el 47,1\% no quiere que Cataluña se convierta en un Estado independiente y el 44,9\% sí quiere. Como vemos, la tercera opción se ha repartido aquí, con cierta ventaja para la no independencia, lo que no quiere decir que esa tercera opción se haya encontrado cómoda al tener que elegir tan drásticamente entre dos únicas opciones.

Es interesante señalar que la cifra del $35,5 \%$ de los que optarian por una Cataluña independiente, es casi diez puntos inferior a lo que preferían esta opción en octubre de 2014 (45,3\%) y ha disminuido casi 5 puntos desde octubre de 2017 (40,2\%), fecha en la que se realizó el referéndum. Probablemente a medida que parte de la población se daba cuenta de que la cosa no era tan fácil como la habian pintado en principio sus dirigentes, y en especial que la Unión Europea no iba a aceptar sin más una Cataluña independiente, especialmente si se hacía en contra del deseo de Madrid. En todo caso, ese $40,2 \%$ de partidarios de la independencia que recogía el barómetro del CEO en octubre de 2017 contrasta con el resultado "oficial" del referéndum, que daba al sí un 90,18\% de los votos emitidos. Claro que como la participación fue, también "oficialmente", del 43,03\%, resultaría que había votado a favor de la independencia un 38,8\% de la población, lo que se parece más al dato ofrecido por el barómetro, considerando que la participación fue masiva por parte de los que deseaban la independencia y residual por los que no la deseaban (7,83\% de los votos emitidos, 3,14\% de la población), y que además los resultados "oficiales" del referéndum son altamente discutibles, como ya hemos comentado, tanto por las irregularidades en la votación como por la falta de control independiente en el recuento.

También es significativo observar, que ese 40,2\% que el CEO atribuye a los independentistas en octubre de 2017 (que sube ligeramente en abril de 2018 al 40,8\%), está sensiblemente por debajo del porcentaje que consiguieron los tres partidos que propugnaban la independencia (JxC, ERC, CUP) en las elecciones del 21 de diciembre, que alcanzaron en su conjunto el 47,50\%. Podría argüirse también, como en la comparación anterior que al haber habido una participación del 79,09\% en esta elección, en realidad votaron a favor de los partidos independentistas un 37,56\% de los censados, lo que también estaría más cerca de la estimación ofrecida por el CEO. Pero además muchos analistas han señalado que los partidos independentistas estarian recibiendo votos de personas no favorables a la independencia - o dudosos - que piensan que estos partidos están en mejores condiciones, y sobre todo con mayor disposición, a obtener de Madrid mejoras sensibles para Cataluña.

Otro aspecto muy interesante del barómetro del CEO, y que atañe directamente a la identidad, es el que se refiere al sentimiento de pertenencia de la población. Según la respuesta a la pregunta 66 , se siente solo catalán el 22,3\% de la población, más catalán que español el 22,6\%, tan español como catalán el 39,1\%, más español 
que catalán el 4,1\% y solo español el 6,5\%.' Esto significa que el 72,4\% de la población de Cataluña se siente también español en mayor o menor medida, y este es un dato objetivo de extraordinario interés. Desde luego, hay otra forma de verlo, que es sumando los que se sienten solo catalanes con los que se sienten más catalanes que españoles, lo que daría un $44,9 \%$ una cifra idéntica a los que quieren que Cataluña se convierta en un estado independiente, según la pregunta 34, (y más cercana a los que votan a partidos independentistas), pero es necesario señalar que la mitad de ellos se sienten de algún modo también españoles y por tanto su apoyo a la independencia no viene tanto de su sentimiento identitario como de las ventajas que piensan que podría reportarles el disponer de un estado independiente.

De todos estos datos, estudiados comparativamente, se puede deducir que hay una parte minoritaria de la ciudadanía de Cataluña que desean inequívocamente separarse de España, que podriamos situar entre el 22,3\% de la población que se siente exclusivamente catalán y el $35,5 \%$ que se declaran directamente independentistas. Este porcentaje sube hasta el 47,5\% que votan a partidos independentistas, es decir estos partidos tienen entre un $12 \%$ y un $25 \%$ de voto "prestado" que los vota porque creen que defienden mejor sus intereses, aunque su posición política o identitaria no sea tan radical, como la que defienden los secesionistas. En el otro lado, tenemos entre un $10.6 \%$ que se sienten más españoles o solo españoles y un 33,3\% que piensan que Cataluña debe ser una región o una autonomía española. Y en medio, un 39,1\% que se siente tan catalán como español, una parte de los cuales podría pertenecer al 23,9\% que desearian un Estado catalán en una España federal, es decir un mayor grado de autonomía. Estos últimos son clave, puesto que si sumamos los federalistas a los independentistas nos da un $59,4 \%$ que se parece bastante al $63 \%$ que cree que la autonomía actual es insuficiente, pero si los sumamos a los regionalistas nos da un $57,2 \%$ que aceptarian continuar dentro de España, bien con el Estatuto actual o con uno mejorado.

De este análisis, basado en datos recogidos por la propia Generalitat de Cataluña, se pueden extraer dos conclusiones. La primera es que una pregunta binaria en la que se ofrece solo la independencia o el mantenimiento actual no se corresponde con la realidad sociológica y política de Cataluña en la que existe una parte importante que se sitúa entre ambas opciones. La segunda es que si se llegara a un acuerdo que ofreciera mayor autonomía a Cataluña, en un sentido federal, esa solución podría ser aceptable para una mayoría de la población catalana, tanto desde el punto de vista identitario, para el 72,4\% que se sienten en algún grado también españoles (aunque no todos estén de acuerdo con el grado de autonomía actual), como desde el punto de vista político para el $57,2 \%$ que no son partidarios de la independencia o prefieren un Estado dentro de una España federal, que es lo que ofrecería el nuevo acuerdo.

\section{Hacia una solución acordada}

Si aceptamos las conclusiones anteriores, está claro que la solución al conflicto catalán consistiría en encontrar una nueva relación entre Cataluña y el resto del Estado que sea suficientemente atractiva para ese grupo de población intermedio que considera que la autonomía actual es insuficiente pero que se sienten tan catalanes como españoles y no apoyan la independencia, e incluso para algunos de los que actualmente la apoyan, que podrian dejar de apoyarla a la vista de un nuevo acuerdo satisfactorio. 
Esta solución siempre tendría enfrente a los más radicales, a aquellos que no quieren saber nada de España y que estarian dispuestos a la secesión a cualquier precio, incluso a costa del aislamiento de la nueva Cataluña y su exclusión por largo tiempo de la Unión Europea. Pero como hemos visto al analizar esta encuesta, cuyos resultados básicos se vienen repitiendo año tras año, esta oposición frontal supondría entre un cuarto y un tercio de la población actual de Cataluña. Si se lograra que un porcentaje cercano a los dos tercios aprobase en referéndum un nuevo estatuto acordado que recogiera la demanda de más autogobierno, mayoritaria en la sociedad catalana, se habría encontrado una salida a la crisis actual, que podría funcionar al menos durante varias décadas. Después, si el proyecto europeo aboca, como es deseable, a una unión política con soberanía compartida, las ideas de independencia de una región de un Estado miembro caerian probablemente en el anacronismo.

Para que fuera aceptable para una mayoría de catalanes, el nuevo acuerdo debería contener al menos los puntos siguientes:

- reconocimiento de Cataluña como nación cultural y política, aunque no soberana, $y$, en consecuencia, de sus competencias exclusivas en materias como lengua, educación, deporte y cultura;

- aceptación del principio de ordinalidad en la distribución de los recursos, es decir que los recursos se gasten donde se originan, incluyendo una cláusula de solidaridad con las regiones más desfavorecidas - suficiente y comprobable que debería ser pactada;

- implementación sistemática del principio de subsidiariedad, por el cual los asuntos se resuelven siempre en el nivel más bajo en el que pueden ser resueltos, siempre que no afecten a los demás, lo que se traduciría en un aumento de sus competencias exclusivas, claramente delimitadas, en las que las instituciones centrales del Estado no podrian entrar;

- creación de una Agencia Tributaria compartida con el Estado;

- reparto geográfico de las instituciones centrales del Estado.

Además habría que encontrar la fórmula para que Cataluña, y el resto de las comunidades, puedan cogobernar, es decir influir en la política del Estado y ser copartícipes de las decisiones que más les afecten como comunidad, más allá de su representación - necesariamente limitada - en el Congreso. Un ejemplo del mecanismo que permite esa corresponsabilidad lo tenemos en el Consejo Federal alemán (Bundesrat), en el que están representados los Estados federados, que votan como tales, y que tiene derecho de veto sobre las leyes que afecten a sus competencias y sobre los cambios constitucionales. Una modificación del Senado español en esta dirección, convertiría a España en un Estado claramente federal y sería muy bien recibida no solo en Cataluña sino también en el País Vasco, en Galicia y en otras autonomías.

No obstante, la viabilidad de una solución de este tipo a corto o medio plazo es escasa, y no precisamente porque no fuera aceptada en Cataluña, sino porque el acuerdo de los partidos políticos españoles para llegar a ella parece altamente improbable. Cualquier modificación constitucional requeriría el acuerdo del principal partido conservador, el PP, que no parece en el momento actual muy proclive a llegar a acuerdos de calado que puedan consolidar a un Gobierno que ha tachado de "ilegítimo". Por el contrario, intentará utilizar cualquier proyecto de acuerdo para estimular la oposición del resto de los españoles, ante la "injusticia" de un trato desigual, y más favorable para Cataluña. 
Aunque este Gobierno lograra alcanzar un acuerdo con las fuerzas politicas catalanas, o una parte importante de ellas, que pudiera ser sometido a referéndum y aprobado mayoritariamente en Cataluña en forma de nuevo Estatuto de Autonomía, el PP, o Vox - que se sitúa en la extrema derecha - podrian recurrirlo de nuevo al Tribunal Constitucional, como ya hizo el PP en 2006, y el Tribunal que tiene una mayoría claramente conservadora, podría de nuevo hacer una interpretación restrictiva de la Constitución y declarar inconstitucionales los avances acordados, lo que es muy probable a luz de la experiencia anterior, con lo que nos encontrariamos de nuevo en la casilla de salida.

La derecha española no ofrece ninguna alternativa para resolver el conflicto catalán, más allá de la aplicación estricta de la ley y la represión de cualquier movimiento o iniciativa que la desafie. La ley debe ser cumplida, por supuesto. Y ningún Gobierno español va a reconocer la soberanía de Cataluña. Pero eso no excluye la búsqueda de una solución política para un problema de carácter esencialmente político, por más que los principales responsables de haber llegado a esta situación hayan sido los dirigentes separatistas catalanes. Hay unos dos millones de catalanes que no están de acuerdo con la situación actual y - tengan o no tengan razón - lo cierto es que no pueden ser ignorados. La represión no ha conseguido hasta ahora calmar las ansias del sector secesionista, sino que por el contrario lo ha estimulado. Intentar obviar la realidad no va a ayudar a resolver el problema. Y es evidente que el mantenimiento de la crisis en Cataluña debilita también a España, tanto internamente como en el papel que juega en la Unión Europea, y en general, en su proyección internacional.

Después del fracaso del proceso soberanista, el problema se sitúa ahora, por tanto, en las fuerzas políticas del Estado. Sin un consenso básico mayoritario, es decir que incluya al principal partido de la oposición, la cuestión catalana no puede resolverse. Y ese consenso va a ser extraordinariamente difícil de alcanzar. Si no se consigue, la situación en Cataluña seguirá estancada, con un riesgo cierto de que evolucione desfavorablemente en el futuro hacia una agudización del conflicto. Tal vez entretanto, habrá que conformarse con "conllevar" el problema sin resolverlo, como señaló el filósofo Ortega y Gasset con ocasión del debate sobre el Estatuto catalán en mayo de 1932, durante la Segunda República. Esperemos que no sea este el caso y que al final las razones de Estado se impongan sobre las partidarias, por el bien de todos.

\section{$\rightarrow$ Referencias / References}

Almirall, Valentí. Lo catalanisme: Motius que el legitimen, fonaments cientifics i solucions pràctiques [Catalanism: reasons that legitimize it, scientific foundations and practical solutions]. Barcelona: RBA Libros, 2013. [In Spanish]

Borrell, Josep, and Joan Llorach. Las cuentas y los cuentos de la independencia [The accounts and stories of independence]. Madrid: Catarata, 2015. [In Spanish]

Jardi, Enric. Companys i el 6 d'octubre [Companys and the 6th of October]. Barcelona: Proa, 1997. [In Spanish] Ortega y Gasset, José. España invertebrada [Invertebrate Spain]. Madrid: Espasa Calpe, 1943. [In Spanish] Ortigosa, José Luis. La cuestión catalana II: Desde junio de 1713 hasta junio de 2018 [The Catalan question II: from June 1713 to June 2018]. Madrid: Vision Libros, 2018. [In Spanish]

Soldevila, Ferran. Història de la prolamació de la República a Catalunya [History of the proclamation of the Catalan Republic]. Barcelona: Curial, 1977. [In Spanish] 


\title{
The Catalan issue: origin, development, and perspectives
}

\author{
José E. De Ayala
}

\section{$\rightarrow$ Abstract}

Catalonia is one of the richest regions in Spain and, thanks to its Statute of Autonomy, it enjoys a self-government comparable to that existing in federal States. It has been part of Spain for as long as Spain exists, but in the course of history there have been several episodes of disagreement and attempts at receiving independence. Since the beginning of this century, a sovereignty process has been launched by supporters of secession, ignorant of the Constitution and Spanish legality, that culminated, in October 2017, with a unilateral declaration of independence, which involved temporary intervention by the Spanish Government and the trial and condemnation of the main leaders, in addition to not being recognized by any country or international organization in the world. Catalan society is plural, formed in part by emigrants from other parts of Spain, and is very divided on this issue. Supporters of independence have never managed to obtain $50 \%$ of the votes in any of the numerous elections carried out, although there is a majority favorable to increasing the level of autonomy. The solution to this conflict can only come with the achievement of a political agreement that establishes a new relationship between Catalonia and the rest of Spain, which satisfies a majority, without the need to break up. But this solution will be difficult because of both the radicalism of some separatist leaders and the lack of agreement between the Spanish parties on how to approach the issue.

https://doi.org/10.46272/24093416-2020-8-2-42-64

\section{Research article}

José Enrique de Ayala, Member of the Advisory Council and the Council of European Affairs, Foreign Policy Observatory of the Alternativas Foundation, Madrid (Spain)

\section{E-mail:}

enriqueayalamarin@gmail.com

For correspondence: 28001, Spain, Madrid, Don Ramón de la Cruz, $39-1^{\circ}$ Izda

For citation: De Ayala, José Enrique. "La cuestión catalana: origen, desarrollo, y perspectivas" [The Catalan issue: origin, development and prospects]. Cuadernos Iberoamericanos 8, no. 2 (2020): 42-64. https://doi. org/10.46272/2409-3416-20208-2-42-64. [In Spanish]

Received: 19.06 .2020

Accepted: 02.08.2020

\section{$\rightarrow$ Keywords}

Catalonia, Spain, autonomy, history, process, independence, secessionism

Disclosure statement: No potential conflict of interest was reported by the author. 


\title{
Каталонский вопрос: происхождение, эволюция и перспективы
}

\author{
Х.Э. Де Айала
}

\section{$\rightarrow$ Аннотация}

Каталония является одним из богатейших регионов Испании и, благодаря своему Статуту, имеет уровень самоуправления, сопоставимый с уровнем самоуправления федеральных территорий в других государствах. Каталония была частью Испании со времен ее возникнования, но в истории присутствуют несколько эпизодов противоречий и попыток получения независимости. С начала XXI столетия сторонники сецессии инициировали процесс суверенизации, игнорируя Конституцию и испанское законодательство. В октябре 2017 года инициативы привели к односторонней декларации независимости, за которой последовало временное вмешательство испанского правительства в процесс каталонского самоуправления, судебное разбирательство и осуждение ключевых политических фигур. Независимость не была признана ни одной страной или международной организацией в мире. Каталонское общество является плюралистическим, включающим и иммигрантов из других частей Испании, и по вопросу каталонской автаномии оно весьма расколото. Сторонникам независимости никогда не удавалось набрать 50\% голосов ни в одном из многочисленных избирательных мероприятий, хотя большинство выступает за повышение уровня автономии. Урегулирование этого конфликта может быть достигнуто только при закреплении политического соглашения, удовлетворяющего требованиям большинства и устанавливающего новые отношения между Каталонией и остальной Испанией, без необходимости его разрыва. Тем не менее подобное решение будет трудным как из-за радикализма некоторых сепаратистских лидеров, так и из-за отсутствия согласия между

https://doi.org/10.46272/24093416-2020-8-2-42-64

\section{Исследовательская статья}

Хосе Энрике де Айала, член Консультативного совета и Совета по европейским делам Обсерватории по вопросам внешней политики «Fundación Alternativas", Мадрид (Испания)

E-mail:

enriqueayalamarin@gmail.com

Для корреспонденции: 28001, Испания, Мадрид, Дон Рамон де ла Круз, $39-1^{\circ}$ Izda

Для цитирования: De Ayala, José Enrique. "La cuestión catalana: origen, desarrollo, y perspectivas" [The Catalan issue: origin, development and prospects]. Cuadernos Iberoamericanos 8, no. 2 (2020): 42-64. https://doi. org/10.46272/2409-3416-20208-2-42-64. [In Spanish]

Статья поступила в редакцию: 19.06.2020

Принята к публикации: 02.08 .2020

\section{$\rightarrow$ Ключевые слова}

Каталония, Испания, автономия, история, процесс, независимость, сецессионизм

Конфликт интересов: Автор заявляет об отсутствии потенциального конфликта интересов. 